\title{
Selecting the Best Method for Adding Recycled Aggregate and Waste Bags to Asphalt Pavement
}

\author{
Feras Al Adday \\ Middle East University, Amman, Jordan, falkhalil@meu.edu.jo
}

\begin{abstract}
Abstract: Large quantities of natural aggregates (NA) are associated with the successive stages of infrastructure construction and maintenance of highway may consume large amounts of natural resources leading to environmental damage. In addition, unexpected growing of destroyed concrete resulting from severe crisis in the Arab region of the demolition of infrastructures and buildings are one of the motivating future responsibilities facing engineers today.

The key objective of research is to present the practical applications on a recycled aggregate (RA) in asphalt mixes with or without waste bags (WB). The ratio of the WB was calculated depending on the wet and dry method of the mixing process, asphalt modified by the WB by $0,1,2,4,6,8$, and $10 \%$ of asphalt content.

This study showed that $100 \%$ of RA is not used in asphalt mixtures for a high traffic volume. Replacement of 53\% of NA by RA has a great influence on the characteristics of asphalt mixes, where the increase of marshal stability in dry method reached $87 \%$ compared with the $100 \%$ RA. The dry method of mixing RA is more effective than the wet method, where the great increase in stability up to $10 \%$, it can the use of RA and WB in production of asphalt mixes as ecologically alternative.
\end{abstract}

Key words: Recycled Aggregate, Waste Bags, Wet Method, Dry Method, Modified Asphalt.

\section{INTRODUCTION}

Replace NA with RA considers a key step in achieving a circular economical [1]. Moreover, the production of new resources from reusing of waste resources is a new technique intended to reduce the negative effects of increasing a solid waste and decrease the need of new natural materials [2][3]. The use RA resulting from the demolition of residential buildings have been achieved over the past thirty years [4]. The population and economic development of communities has also increased the need for road construction [5]. Furthermore, the highways construction of infrastructures deplete millions of tons of natural aggregates (NA) which have a negative impact on the environment and society [6].
Asphalt mixes are carefully chosen to ensure the ultimate pavement performance throughout service life [7]. Particularly with the increased volume of traffic associated with excessive climate changes [8]. The most affected factors to choose the pavement type in the past, the cost of construction and performance. Now, Sustainability is one of the most important selection factors [9]. Reducing environmental impacts by reducing greenhouse gas emissions, fuel consumption and depletion of natural resources while maintaining good performance compatible with the construction codes, this is known as sustainable paving. [10]. With regard to the addition of admixtures to asphalt mixes, various types of admixtures such as polymers, scrap rubber, and waste solid plastic can be used in asphalt mixes to improve its performance. In additional, it reduce the consumption of asphalt cement and the ecological pollution [11][12]. The methods of mixing asphalt with plastic vary from wet to dry and semi-wet technique. Dry method, the plastic is mixed with hot aggregate and then optimum amount of asphalt is added to the aggregate, which was previously coated with plastic. Wet method: The plastic is melted and carefully mixed with asphalt and then it is added to the aggregate. Semi-wet method, small plastic residues that have not been dissolved in asphalt serve as a modifier for asphalt aggregate [13] [14].

Researches carried out by many specialized organizations indicate the possibility of using the plastic waste (PW) in paving roads and with good effectiveness. One of these researches presented by Adou [15], they used the dry mixing method where the PW was covered aggregate before mixing it with asphalt. The results display that, PW developed the aggregates quality (abrasion, soundness and water absorption), which leads to increase the strength of the pavement (Marshall stability increase of $15 \%$ related to control mix). The opposite use of PW was done by Sevil Köfteci[16], where the wet method of mixing was used. The PW was added to the asphalt at 1,2,3,4\% of asphalt weight, and then the modified asphalt were measured for calculate their properties. The results indicated that the addition of $4 \%$ has a better performance than the other additions in terms of stability. Furthermore, all samples were presented a high resistance of water. Another research conducted by Abu Abdo [17] about using PW, where the effects of adding PW $(0,0.2$, 0.5 , and $1 \%$ of total weight of aggregates) to asphalt mix were examined. Results revealed that using $0.2 \%$ PW would 
Feras Al Adday, International Journal of Emerging Trends in Engineering Research, 8(6), June 2020, 2253 - 2258

increase the asphalt mix performance. Also, using $0.5 \% \mathrm{PW}$ would create a sustainable pavement.

As for the use of RA in asphalt mixtures, researches indicate that there are a decrease in asphalt mix performance by increasing the proportion of RA and this is what both Qasrawi and Asi [9] reached in their researches. The NA was substituted at $0,25,50,75$ and $100 \%$ by RA. It also showed that the $25 \%$ and more of RCA could not be used in asphalt mixes for heavy-traffic. Both Pourtahmasb and Karim [18]; Mills-Beale and Z. You [19] also proved that RA is suitable for light traffic if added in specific quantities. The same result was obtained by Bhusal and others [20] through their research, where they replaced RA by NA at ratios $0,20,40$, 60,80 , and $100 \%$. Investigations have shown that the increase in the RA leads to the increase in asphalt cement content, and also showed that adding RA to asphalt mixes are not recommended. The same behavior between the proportion of RA and asphalt content were obtained by Radević and others [21], but they revealed that RA can be used in asphalt mixes.

Regarding the use of RA and WB together has done by Humeidawi [22], he studied the option of adding WB to RA in making of asphalt mixes. It was stated that adding an asphalt improved by WB to the RA cause increase stability value equal to $10 \%$ related to asphalt mixes without WB.

Based on the above, this research will focus on a comparative analysis between the wet and dry methods of mixing of WB with asphalt or aggregates, where the following ratios were selected at $15,30,45,60$ and $75 \%$ as replacement ratio of NA. Thus examine the possibility of adding RA to asphalt mixes for heavy traffic pavement.

\section{MATERIALS AND PROCESSES}

The starting point of the project was the search for sources of RA and WB. RA was brought from some of the demolished residential buildings, and then broke by hand with a hammer. WB are colored bags to pack the needs of the markets have been obtained from some residential areas near the university, where they were shredded into a small pieces ranging from 2 $\mathrm{mm}$ to $4.5 \mathrm{~mm}$, specific gravity of WB was 0.96 (ASTM D792). The characteristics of the RA and NA are then determined.

L A abrasion test (ASTM C131 - 81) was achieved. L A value was $27.14 \%$ and $41.24 \%$ for NA and RA, respectively. It is bigger than acceptable value (30\%) for RA [23]. Specific gravity for NA was 2.57(coarse), 2.64(fine), and 2.72 (filler), and for RCA of 2.23, 2.41, and 2.69, respectively. The water absorption of NA was $2 \%$, and the RA was $7.12 \%$, it is higher than the acceptable specification (3.7\%) [24]. High rate of water absorption is due to the amount of cement mortar surrounding NA. The gradation of NA and RA, and asphalt cement specifications were tested in relation to a Jordanian requirement as illustrated in Table1 [25].
Increasing proportions of asphalt were added to NA and RA according to the following $5,5.5,6,6.5,7,7.5$, and $8 \%$ by total weight. The number of were 36 according to Marshall Method (ASTM D1559-82). From this process the optimum content of asphalt (OCA) was collected for RCA and NA. After determining OCA, a several quantities of RA ranging from $19 \mathrm{~mm}$ to $4.75 \mathrm{~mm}$ were replaced by NA to prepare an 18 samples from RA and NA, where replacement ratio were 0 , $15,30,45,60$, and $75 \%$ of RA. Reference mixes represent the mixes comprising $100 \%$ of RA.

Table 1: Aggregates Gradation and Asphalt specifications

\begin{tabular}{ccc}
\hline \multicolumn{3}{c}{ Aggregate Gradation (ASTM C131) } \\
\hline \multirow{3}{*}{ Fieve size } & \multicolumn{2}{c}{ Coarse Aggregate } \\
\cline { 2 - 3 } & Fine Aggregate & 100 \\
\hline 1 inch & 100 & 97.24 \\
\hline $3 / 4$ inch & 100 & 60.65 \\
\hline $1 / 2$ inch & 100 & 33.59 \\
\hline $3 / 8$ inch & 100 & 2.88 \\
\hline$\# 4$ & 99 & 0.57 \\
\hline$\# 8$ & 86 & 0 \\
\hline$\# 16$ & 50 & 0 \\
\hline$\# 30$ & 30 & 0 \\
\hline$\# 50$ & 16 & \\
\hline$\# 200(75 \mathrm{mc})$ & 7 & \\
\hline & & 0 \\
\hline
\end{tabular}

Asphalt specifications

\begin{tabular}{ccc}
\hline Test & value & Method \\
\hline Softening point & $51.45^{\circ} \mathrm{C}$ & ASTM D-36 \\
\hline Ductility & $77 \mathrm{~cm}$ & ASTM D113 \\
\hline Penetration & $64 \mathrm{~mm}$ & ASTM D-5 \\
\hline Flash point & $286^{\circ} \mathrm{C}$ & AASHTO T48 \\
\hline Fire point & $314^{\circ} \mathrm{C}$ & AASHTO T48 \\
\hline Specific gravity & 1.03 & ASTM D-70 \\
\hline
\end{tabular}

The final stage was to prepare the compound mixes NA (53\%)-RA (47\%) according to the wet and dry method of asphalt mixing. The wet procedure, an asphalt heated to 105 ${ }^{\circ} \mathrm{C}$ until unsolidified state and then WB regularly added into asphalt while maintaining the temperature of $160170 \mathrm{oC}$ to avoid thermal deprivation of WP. To ensure a wider spread of WB in asphalt, the mix was slowly stirred to prepare a homogeneous mixture. WB was added at 1, 2, 4, 6, 8 and $10 \%$ of OCA. The resulting mix was used to covering the hot aggregate to confirm homogenously spreading over aggregates.

Dry method includes adding WB directly into aggregates. Temperature is also retained about $160^{\circ} \mathrm{C}-170^{\circ} \mathrm{C}$ to heat RA of size $4.75-0.075 \mathrm{~mm}$. The hot RA blended with the WB to achieve a uniform distribution of WB over RA. Finally a lubricant surface is produced around RA, after cooling the 
lubricant surface crystallizes, and then asphalt add asphalt according to OCA. The number of samples prepared for calculating the optimum content of WB were 72 (18 for NA, 18 dry NC-RA, 18 wet NC-RA and RA).

\section{TESTING PROGRAM}

\subsection{Determine The Optimum Content Of Asphalt (OCA) For NA and RA}

Asphalt mixes with NA have a much greater stability compared to asphalt mixes with RA as shown in the Figure1. The maximum stability of RA mixes was $715 \mathrm{~kg}$, it is less than the minimum standard limit of stability for heavy traffic $(816 \mathrm{~kg})$ [26]. This may be due to the greater ratio of L. A abrasion. As for a specific gravity, Figure 2 displays a significant differences between NA mixes and RA mixes, this is related to the weak properties of RA. Bhusal and others [20] has reached the same conclusion.

Flow is generally an important indicator of Marshall's stiffness, high flow indicates low stiffness and vice versa. Figure 3 illustrates this inverse relationship, where the flow of NA mixtures has less value than the mixtures of RA. The air void - the asphalt ratio relationship is shown in Figure 4, it is clear that air voids decreasing progressively as asphalt ratio increase for NA and RA mixes. RCA mixtures have a higher percentage of voids, this behavior is interpreted as having high porosity, it result in to increase asphalt ratio. Investigation results are consistent with the results of Pourtahmasb and Karim [7]. The OAC for RA and NA mixes can be determined from Figures. 1, 2 and 4, OAC was 7.6\% for RA and $6.2 \%$ for NA of the weight mixtures.

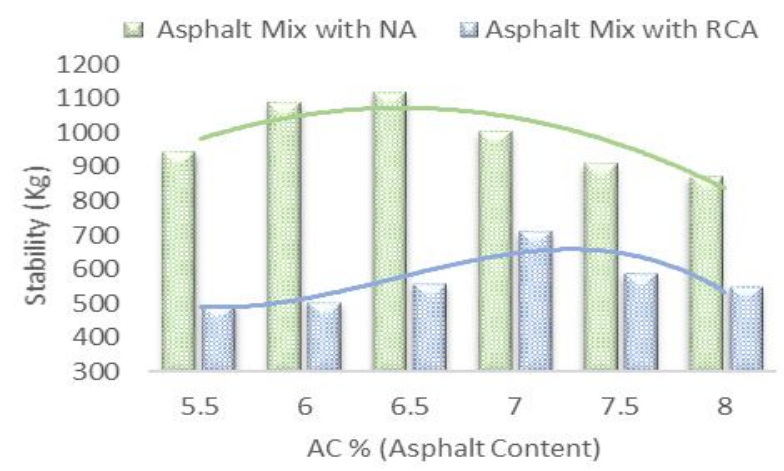

Figure 1: Represent Stability with Asphalt Ratio \%

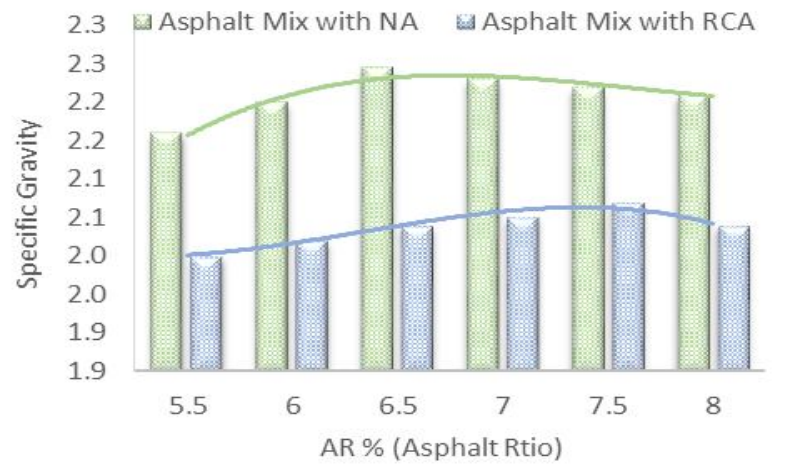

Figure 2: Represent Specific Gravity with Asphalt Ratio \%

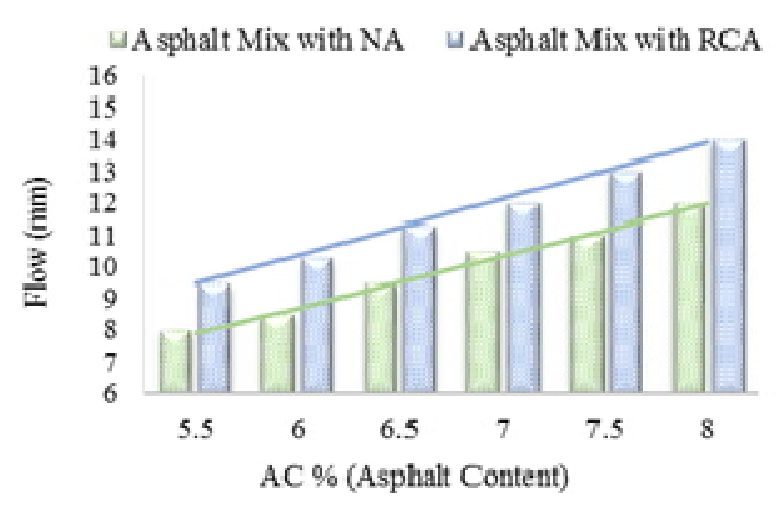

Figure 3: Represent Flow with Asphalt Ratio\%

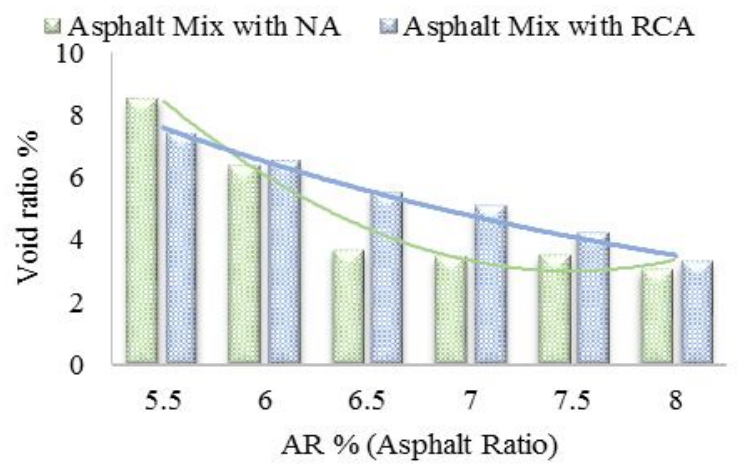

Figure 4: Represent Void Ratio with Asphalt Ratio \%

\subsection{Determine The Optimum Content Of RA}

As indicated in the previous paragraph, RA cannot be used for heavy traffic pavements, therefore, the research was based on replacing increasing proportions of RA with NA at OAC of 7.6\%. As demonstrated in Figures. 5, 6 the specific gravity and stability increased gradually as NA percentages increase mixtures. In contrast, the addition of NA cause decline in flow and air void values as illustrated in Figures. 7, 8, and this results correspond to the conclusions reached by Qasrawi and Asi [9]. Based on the minimum limit of stability and satisfactory void ratio (3-5\%), all RA that are retained on sieve $4.74 \mathrm{~mm}$ will be replaced with NA, 53\% of coarse-NA and $47 \%$ of fine-RA. The composite mixtures is NA (53\%)-RA (47\%).

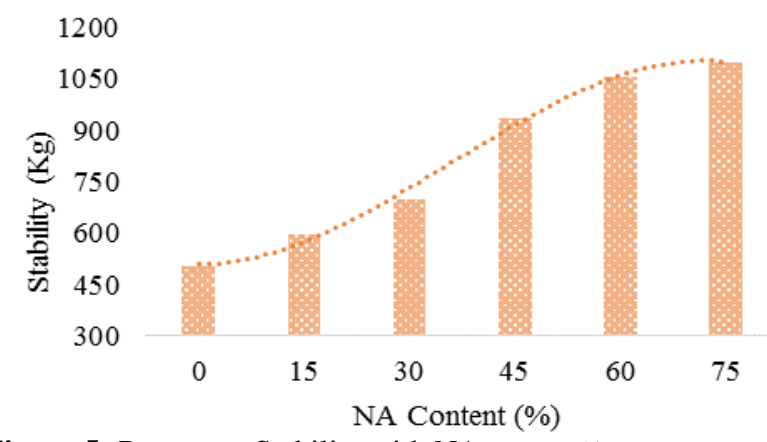

Figure 5: Represent Stability with NA content\% 


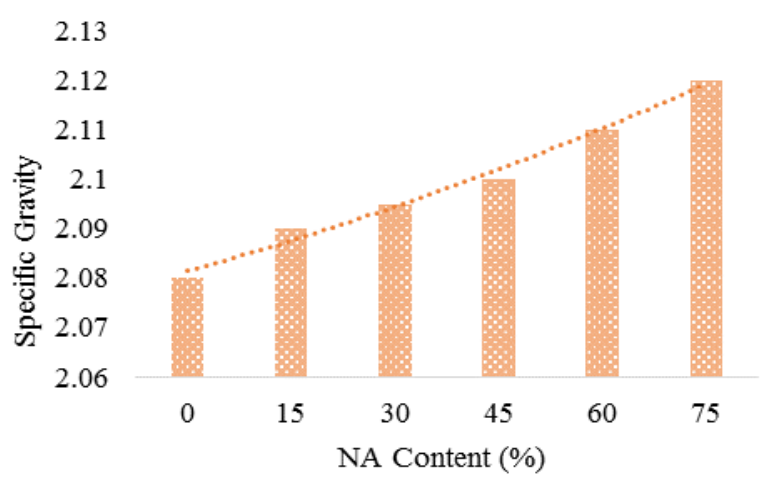

Figure 6: Represent Specific Gravity with NA content $\%$

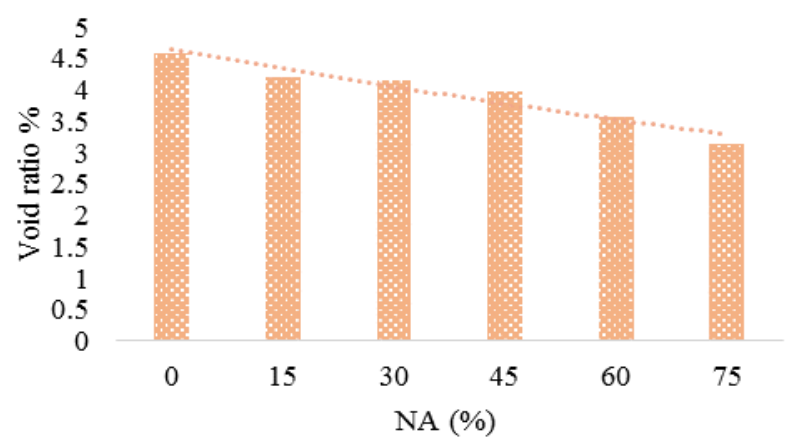

Figure 7: Represent Flow with NA content\%

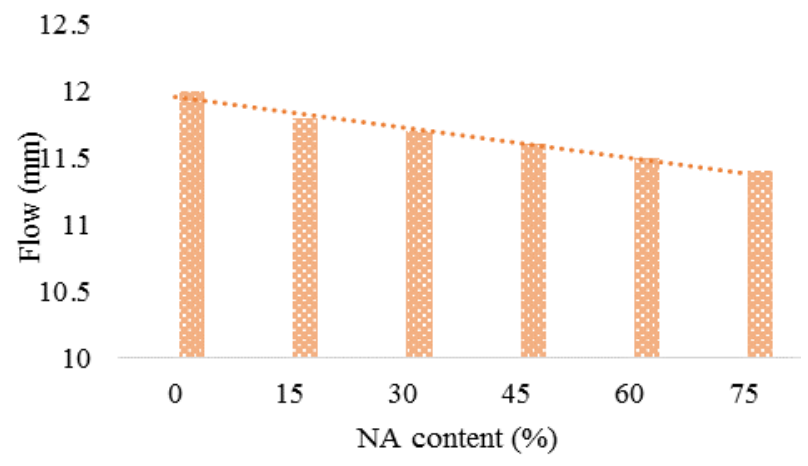

Figure 8: Represent Void ratio \% VS NA content \%

\subsection{Determine The Optimum Content Of WB}

To determine the optimum content of $\mathrm{WB}$, an analytical comparison between the dry and wet method of mixing WB with asphalt was complete. NA (53\%)-RA (47\%) by wet method, NA (53\%)-RA (47\%) by dry method, NA (100\%), and RA $(100 \%)$ are mixtures that have been tested. WB has added as admixture at ratios $0,2,4,6,8$, and $10 \%$ of OAC (7.6\%) for two methods.

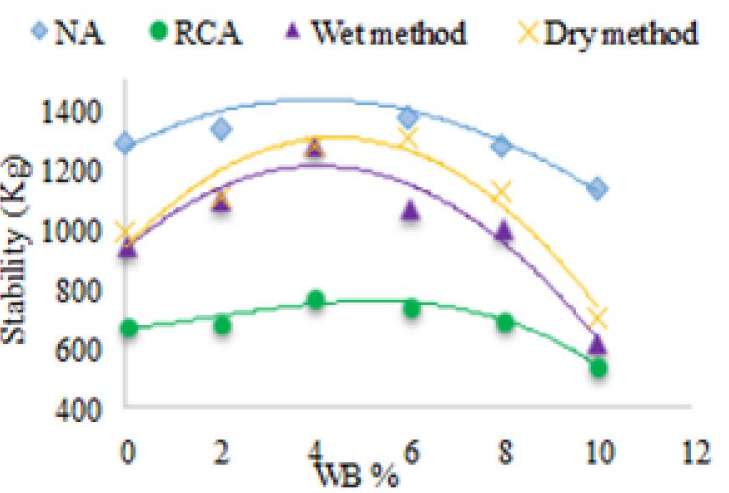

Figure 9: Represent Stability VS WB\%

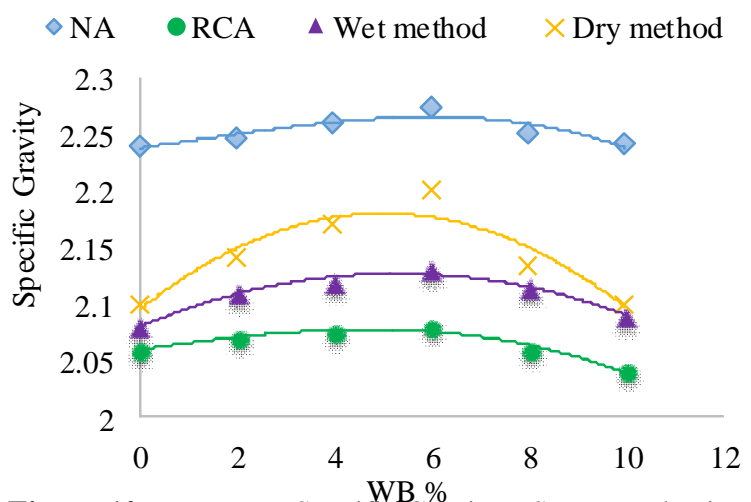

Figure 10: Represent Specific Gravity VS Waste Plastic\%

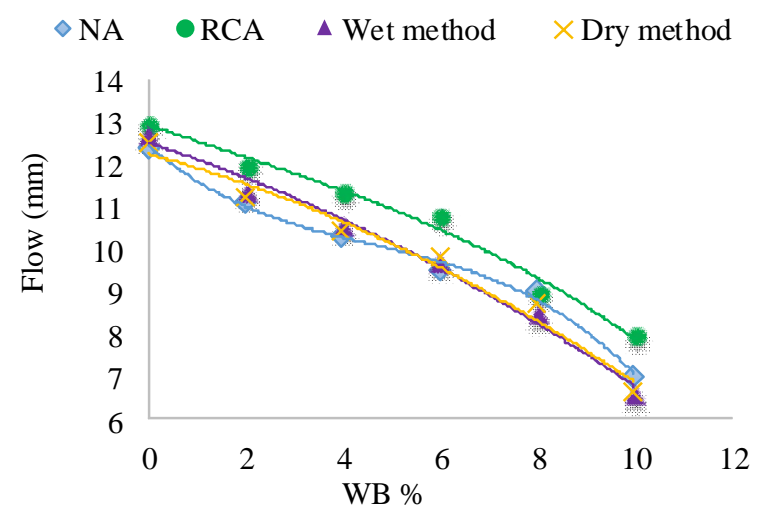

Figure 11: Represent Flow VS Waste Plastic\%

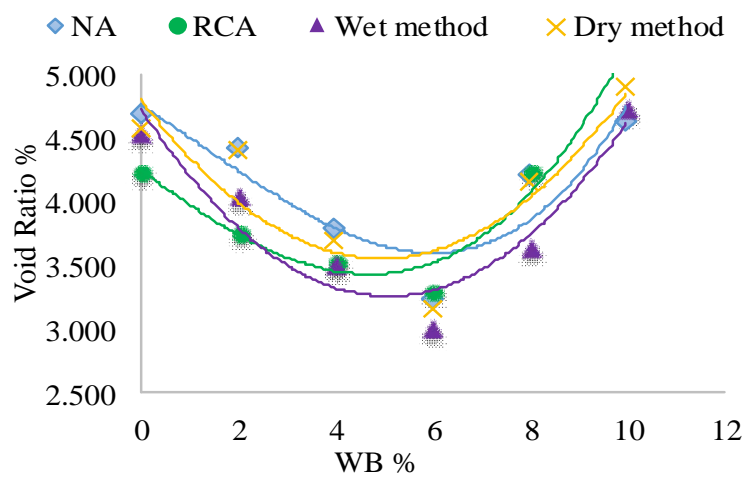

Figure 12: Represent Void Ratio VS Waste Plastic\% 
Feras Al Adday, International Journal of Emerging Trends in Engineering Research, 8(6), June 2020, 2253 - 2258

Stability of NA-RA mixtures in the dry method have higher value more than the wet method, where they surpassed the standard limit and reached $1312 \mathrm{~kg}$ at $6 \%$ of $\mathrm{WB}$, while the stability for the wet method was $1280 \mathrm{~kg}$ at $4 \%$ of WB. The RA mix in dry method is approaching its behavior with NA mixtures as shown Figure 9. Such outcomes have been achieved by Al- Radević and other [21]. In term to RA-100\% mixes have lower stability and is still not used for heavy traffic pavement. It is clear any the increase of WB after $6 \%$ in dry method decline the stability mixes. The addition of WB leads to the development of the property of bonding of asphalt around aggregate and thus increase its strength (WB binds initial with RA before asphalt comes in). After $6 \%$ of WB this behavior changes and the stability begins to decrease due to the process of hardening asphalt.

For the specific gravity, NA-RA mixes in the dry method has maximum value at $6 \%$ of WB by the weight of asphalt as revealed in figure 10 . After this $6 \%$ of WB the specific gravity drop. As explained in the previous paragraph about the formation of a stiffer mixture leads to this behavior. The flow decrease as WB content decrease in all mixtures as shown in Figure11. This behavior is due to form a solid modified mix may cause a lower flow.

From Figure 12, the void ratios drop as WB ratio increase till the lowest values after these value the void ratios increase for all mixes. Also, $4 \%$ of void ratio is average requirements (3\%-5\%). In the dry method, $2 \%$ of WB corresponds to $4 \%$ of void ratio for NA- RCA mixes, $1.7 \%$ of WB for wet method for NA-RA mixes and $4 \%$ of WB for $100 \%$ of RCA at $4 \%$ of void ratio.

The optimum WB of NA - RA is $4.6 \%$ and $3.3 \%$ of asphalt for dry and wet method, respectively. At these values, the flow was $10.1 \mathrm{~mm}$ for dry method and $11.2 \mathrm{~mm}$ for wet method, where typical flow standards are from $8 \mathrm{~mm}$ to $14 \mathrm{~mm}$. This means the possibility of using WB and RA in both method in asphalt mixes for heavy traffic pavement.

\section{CONCLUSION}

An investigational study focused on assessing the engineering properties of a modified asphalt mixes that have used RA and WB. Analytical comparison between dry and wet methods of mixing WB with asphalt or RA has completed. Depending on the results of experiments attained, these results can be summarized as follows:

1. The use of RA alone without additives has negative effects on the properties of asphalt mixes. Marshall's stability values did not reach the satisfactory limits in the worldwide codes for heavy traffic paving. However, a certain percentage of NA with WB can be added to produce asphalt mixtures for high traffic paving. It can be considered a sustainable solution to the highway.

2. Covering of the RA surface with WB according to the dry method is relatively better than the wet method. The results showed that the values of stability and specific gravity are greater in the dry method, where the stability has improved of $87 \%$ and $65 \%$ comparable with RCA mixes without WB in dry and wet method respectively.

3. WB increased the asphalt properties and quality of RA in asphalt mixes. It maintains the flexibility property when added with a certain percentage, and thus a greater value stability of pavement.

4. Additionally, the optimum WB was $4.6 \%$ and $3.3 \%$ of asphalt ratio to the dry and wet method, respectively.

5. Utilizing WB in asphalt mixes will deduct asphalt content about $4.6 \%$.In addition, it is a suitable solution to the problem of asphalt consumption. The use of RA and WB in the pavement can also be considered a solution to reduce the occupied space in waste.

\section{ACKNOWLEDGMENT}

The author are grateful to the Middle East University, Amman, Jordan for the financial support granted to cover the publication fee of this research article.

\section{REFERENCES}

1. S. Koxa, G. Vanroelena, J. Van Herckb, H. de Kremb, B. Vandorena, 2019. Experimental evaluation of the high-grade properties of recycled concrete aggregates and their application in concrete road pavement construction. Case Studies in Construction Materials. https://doi.org/10.1016/j.cscm.2019.e00282.

2. Hussein I. Abdel-Shafy and Mona S.M.Mansour., 2018. Solid waste issue: Sources, composition, disposal, recycling, and valorization. Egyptian Journal of Petroleum. Pages 427-1384. https://doi.org/10.1016/j.ejpe.2018.07.003.

3. Aymen Awad, Firas Al Bajari and Feras Al Adday, 2019. A Case Study on Rainwater Harvesting and Reuse in Jordan. International Journal of Emerging Trends in Engineering Research Volume 7. No. 11, https://doi.org/10.30534/ijeter/2019/017112019.

4. Zainab Z. Ismail, Enas A. AL-Hashmi, (2007). Use of waste plastic in concrete mixture as aggregate replacement. ELSEVIER journal, Available online at www.sciencedirect.com, waste Management 28 (2008) 2041-2047.

https://doi.org/10.1016/j.wasman.2007.08.023

5. D. El Tahan - A. Gabr1, S. El Badawy, M. Shetawy, (2018). Evaluation of recycled concrete aggregate in asphalt mixes. Innovative Infrastructure Solutions, ttps://doi.org/10.1007/s41062-018-0126-7, (C) Springer International Publishing AG, part of Springer Nature 2018. January 2018.

6. Hisham Qasrawi , Ibrahim Asi, (2016). Effect of bitumen grade on hot asphalt mixes properties prepared using recycled coarse concrete aggregate. ELSEVIER journal, journal homepage: 
Feras Al Adday, International Journal of Emerging Trends in Engineering Research, 8(6), June 2020, 2253 - 2258

www.elsevier.com/locate/conbuildmat, construction and building materials 121 (2016) 18-24.

7. Mohammad Saeed Pourtahmasb, (2016). Feasibility of using recycled concrete aggregate in dense-graded and gap-graded hot mix asphalts. Doctor of Philosophy - thesis - University of Malaya-Faculty of engineering, Kuala Lumpur, 2016.

8. Johnson Kwabena Appiaha, Victor Nana Berko-Boatenga, Trinity Ama Tagbor, (2017), Case Studies: Use of waste plastic materials for road construction in Ghana. ELSEVIER journal, journal homepage: www.elsevier.com/locate/cscm, case studies in construction materials 6 (2017) 1-7.

9. Brian Prowell, (2008). Carbon Footprint: How Does HMA Stack Up?. Report used with Permission of the National Asphalt Pavement Association. Summer 2008.

10. Haopeng Wang, Xueyan Liu, Panos Apostolidis, Tom Scarpas, (2018). Review of warm mix rubberized asphalt concrete: Towards a sustainable paving technology. ELSEVIER journal, journal homepage: www.elsevier.com/locateljclepro, journal of cleaner production 177 (2018) 302-314.

11. Feras Al Adday, Fatima Alsaleh, 2020. Study the Possibility of Using the Modified Asphalt Mixtures with Waste Plastic in High-Temperature Areas. International Journal of Emerging Trends in Engineering Research. Volume 8. No. 4. doi.org/10.30534/ijeter/2020/23842020.

12. Feras Al Adday, Aymen Awad, 2019. Pre-Wetting of Recycled Concrete as Alternative of Chemical, Natural and Industrial Waste Additives. International Journal of Innovative Technology and Exploring Engineering (IJITEE). Volume-8 Issue-12, October 2019, DOI: 10.35940/ijitee.L3166.1081219

13. Basim H. Al-Humeidawi, (2014). Utilization of Waste Plastic and Recycle Concrete Aggregate in Production of Hot Mix Asphalt. Al-Qadisiya Journal for Engineering Sciences, Vol. 7, No. 4. October 2014.

14. Aymen Awad and Feras $\mathrm{Al}$ adday, 2017. Utilization of waste plastics to enhance the performance of modified hot mix asphalt. International Journal of GEOMATE, Dec., 2017, Vol. 13, Issue 40, pp.132-139. DOI: https://doi.org/10.21660/2017.40.170603.

15. Freshnel Adou, Boateng Ampadu, Nana Kwesi Agyepong, and Olivia Naa-Afi Soli. 2018. Assessing Plastic Waste Usage as Additives in Flexible Asphalt Mix for Road Construction. Civil and Environmental Research. ISSN 2224-5790 (Paper) ISSN 2225-0514 (Online).

16. Sushanta Bhusal, Xiaojun Li, and Haifang Wen, (2011). Evaluation of effects of recycled concrete aggregate on volumetrics of hot-mix asphalt. Transportation Research Record: Journal of the Transportation Research Board, No. 2205, Transportation Research Board of the National Academies, Washington, D.C., 2011, pp. 36-39. DOI: 10.3141/2205-05, January 2011.
17. Ahmad M. Abu Abdo, 2017. Investigation the effects of adding waste plastic on asphalt mixes performance. Journal of Engineering and Applied Sciences. VOL. 12, NO. 15.

18. Mohammad Saeed Pourtahmasb and Mohamed Rehan Karim, (2014). Performance Evaluation of Stone Mastic Asphalt and Hot Mix Asphalt Mixtures Containing Recycled Concrete Aggregate. Hindawi Publishing Corporation, Advances in Materials Science and Engineering, Volume 2014, Article ID 863148, 12 pages, http://dx.doi.org/10.1155/2014/863148.

19. Julian Mills-Beale, Zhanping You, (2010). The, Construction and Building Materials 24 (2010) 230-235. Journal homepage: www.elsevier.com/locate/conbuildmat. October 2009.

20. Yadav Santosh, Saxena Anil Kumar, Arora T.R, (2013). Performance Evaluation of Waste Plastic and Bitumen Concrete mix in Flexible Pavements. International Journal of Scientific \& Engineering Research, Volume 4, Issue 10, ISSN 2229-5518, October 2013.

21. Aleksandar Radević, Aleksandar Đurekovi, Dimitrije Zakić, Goran Mladenović, (2017). Effects of recycled concrete aggregate on stiffness and rutting resistance of asphalt concrete. Constr. Build. Mater. 136 (2017) 386-393, http://dx.doi.org/10.1016/j.conbuildmat.2017.01.043.

22. Basim H. Al-Humeidawi, (2014). Utilization of Waste Plastic and Recycle Concrete Aggregate in Production of Hot Mix Asphalt. Al-Qadisiya Journal for Engineering Sciences, Vol. 7, No. 4. October 2014.

23. Yoon-Ho Cho, Taeyoung Yun, In Tai Kim, Nyoung Rak Choi, (2011). The application of recycled concrete aggregate (RCA) for hot mix asphalt (hma) base layer aggregate. KSCE Journal of Civil Engineering (2011) 15(3):473-478.

24. Fathei Ramadan salehlamein, Mochamad .Solikin, Ir.sriSunarjono , (2015). Effect of Recycled Coarse Aggregate on Concrete Properties. Post Graduate Civil Engineering Programs Universities, Indonesia, Higher polytechnics institute, Bani Waleed, Libya.

25. Sunaryo, Marwan Efendy, Sarjito, Nur Saifullah. Kamarrudin. Pyrolysis of Plastic Waste as an Alternative Fuels in Spark Ignition Engine. International Journal of Emerging Trends in Engineering Research, Volume 7. No. 11, https://doi.org/10.30534/ijeter/2019/097112019.

26. Nicholas J. Garber, Lester A. Hoel, (2009). Traffic and Highway Engineering, fourth edition. University of Virginia, printed in the United States of America (1 234 567111009 08), cengage learning. 